\title{
FATIGUE LIFE PREDICTION BASED ON MACROSCOPIC PLASTIC ZONE ON FRACTURE SURFACE OF AISI-SAE 1018 STEEL
}

\author{
G.M. Domínguez Almaraz ${ }^{1}$ M. Guzmán Tapia ${ }^{2}$, E.E. Tapia Silva² \\ and E. Cadenas Calderón ${ }^{1}$
}

${ }^{1}$ Universidad Michoacana de San Nicolás de Hidalgo, Facultad de Ingeniería Mecánica Santiago Tapia No. 403, Col. Centro, 58000, Morelia, Michoacán, México Tel.: 00524433223500 ext. 3102, Fax: 00524433223500 ext. 3107

E-mail: dalmaraz@umich.mx

${ }^{2}$ Universidad Tecnológica de Morelia, Ingeniería en Mantenimiento Industrial Vicepresidente Pino Suárez No. $7504^{\text {a }}$. etapa, Ciudad Industrial, 58200, Morelia

Michoacán, México

\begin{abstract}
This paper deals with rotating bending fatigue tests at high speed $(150 \mathrm{~Hz})$ carried out on AISI-SAE 1018 steel with a high content of impurities (non metallic inclusions), for which the high experimental stress inside the specimen is close to the elastic limit of the material. Simulations of rotating loading are obtained by Visual NASTRAN software in order to determine the numerical stresse and strain distributions inside a hypothetical homogeneous specimen; later, this information is used for the experimental set up. A general description of experimental test machine and experimental conditions are developed and then, the experimental results are presented and discussed according the observed failure origin related to the non metallic inclusions and the associated high stress zones. Finally, a simple model is proposed to predict the fatigue life for this non homogeneous steel under high speed rotating bending fatigue tests close to the elastic limit, based on the rate between the visual macro-plastic deformation zone at fracture surface and the total fracture surface, together with the crack initiation inclusion (or inclusions) located at this zone.
\end{abstract}

Keywords: Rotating bending fatigue; Metallic alloy; Non metallic inclusions; Plastic strain; Fatigue endurance model.

\section{INTRODUCTION}

In the last 40 years modern industries such as the automotive, aerospace, high speed train, electricity production industry and others have become more efficient in energy use, thanks to the development of new materials and the improvement of their physical and mechanical properties (Sohar et al., 2008; Jung and Schnell, 2008; Dominguez Almaraz, 2008; Nový et al., 2007). Very often in these industries, the mechanical elements or systems undergo oscillating loads leading to mechanical fatigue. Under these conditions, it is of great interest to carry out investigations on fatigue endurance to prevent material and human catastrophes. Furthermore, in many cases the oscillating mechanical loads which occur are of high frequencies and attain $150 \mathrm{~Hz}$ or more. A simple and non expensive method to investigate the fatigue endurance of metallic alloys in the high frequency fatigue regime is the rotating bending fatigue machine. In this work is presented a new high speed $(150 \mathrm{~Hz})$ rotating bending fatigue machine (patent 
No. MX/a/2007/005748 in process), to carry out fatigue tests at high speed under loading conditions close to the elastic limit of the material. This fatigue loading condition was chosen in this work because a principal matter is the relationship between visual macro-plastic deformation zones and crack initiation inclusion (or inclusions), and the fatigue endurance of this material when the fatigue life is comprised between: 4 x $10^{4}$ and $3 \times 10^{5}$ cycles. This steel undergoes load and fatigue conditions as mentioned above under industrial applications: AISI-SAE 1080 low carbon steel is a versatile welding and well hardening material involved in many industrial applications, suitable for parts requiring cold forming, such as crimping, bending, or swaging. Especially suitable for carburized parts requiring soft core and high surface hardness, such as gears, pinions, worms, king pins, ratchets, rods... This metallic alloy with impurities (non metallic inclusions) was selected to carry out the tests. Reduction of impurities control was not implemented, in order to investigate the effect on fatigue endurance.

\section{EXPERIMENTAL PARAMETERS}

\section{Testing material}

Tables 1 and 2 present the chemical composition and mechanical properties of industrial steel.

Table 1: Chemical composition

\begin{tabular}{lc}
\hline \multicolumn{1}{c}{ Chemical composition } & Wt $(\boldsymbol{\%})$ \\
\hline $\mathrm{Fe}$ & $98.81-99.26$ \\
$\mathrm{C}$ & $0.15-0.20$ \\
$\mathrm{Mn}$ & $0.60-0.90$ \\
$\mathrm{Si}$ & $\approx 0$ \\
$\mathrm{P}$ (Max.) & 0.04 \\
$\mathrm{~S}$ (Max.) & 0.05 \\
\hline
\end{tabular}

Table 2: Mechanical properties

\begin{tabular}{lc}
\hline \multicolumn{1}{c}{ Parameter } & Value \\
\hline Density $\left(\mathrm{Kg} / \mathrm{m}^{3}\right)$ & 7850 \\
Hardness, Brinell & 197 \\
Tensile Yield Strength (MPa) & 386 \\
Ultimate Tensile Strength (MPa) & 634 \\
Modulus of Elasticity (GPa) & 200 \\
Poisson's Ratio & 0.29 \\
Elongation at Break (\%) & 27 \\
\hline
\end{tabular}

\section{Dimensions of specimen}

Specimens with an hourglass shape were used to carry out the tests; no international standardization is available for the rotating bending fatigue specimen. Figure 1 shows the dimensions of specimen in $\mathrm{mm}$. The narrow section diameter $D_{0}$ is a principal geometrical parameter for load application and stress concentration inside the specimen; all tests were carried out with $D_{0}=4 \mathrm{~mm}$. 


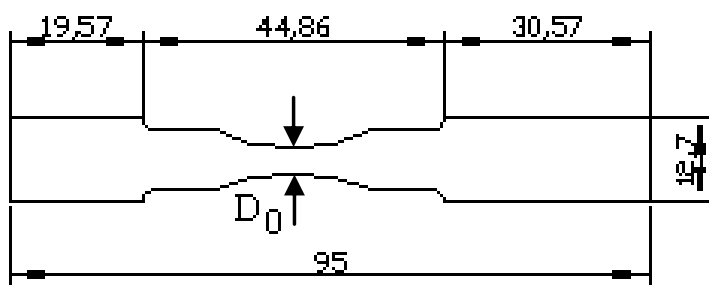

Figure 1: Dimensions (mm) of specimen.

\section{Testing machine}

The testing machine was developed in the Faculty of Mechanical Engineering, University of Michoacan (UMSNH), Mexico, the world's first rotating bending fatigue machine working at $150 \mathrm{~Hz}$ : most rotating bending fatigue machines work close to 50 $\mathrm{Hz}$ (Nakajima et al., 2010; Sakai et al., 2010). Figure 2 shows the principal components of this machine: electrical motor $\mathbf{1}$ provides motion to rotating axis $\mathbf{2}$ which is connected to specimen 3. The electronic system (not shown) located close to the back side of the rotating axis counts the number of cycles; it is composed of an electronic sensor, electronic card, personal computer and software. The applying load system $\mathbf{4}$ is simplified in Figure 2; it consists of a bearing at the free side of the specimen allowing of communicating the applied load $\mathrm{P}$, and a spring frame supporting the bearing. When the specimenstarts to fail during the test, the distance between this one and the proximity sensor $\mathbf{5}$ increases; this leads to the automatic stop of the electric motor and test by the electric relay 6. Special care was taken for the alignment between the specimen and the rotating axis: any little misalignment (higher than $0.3 \mathrm{~mm}$ at the free side of the specimen) induces significant torsion stress at the narrow section of the specimen and a possible early fracture.

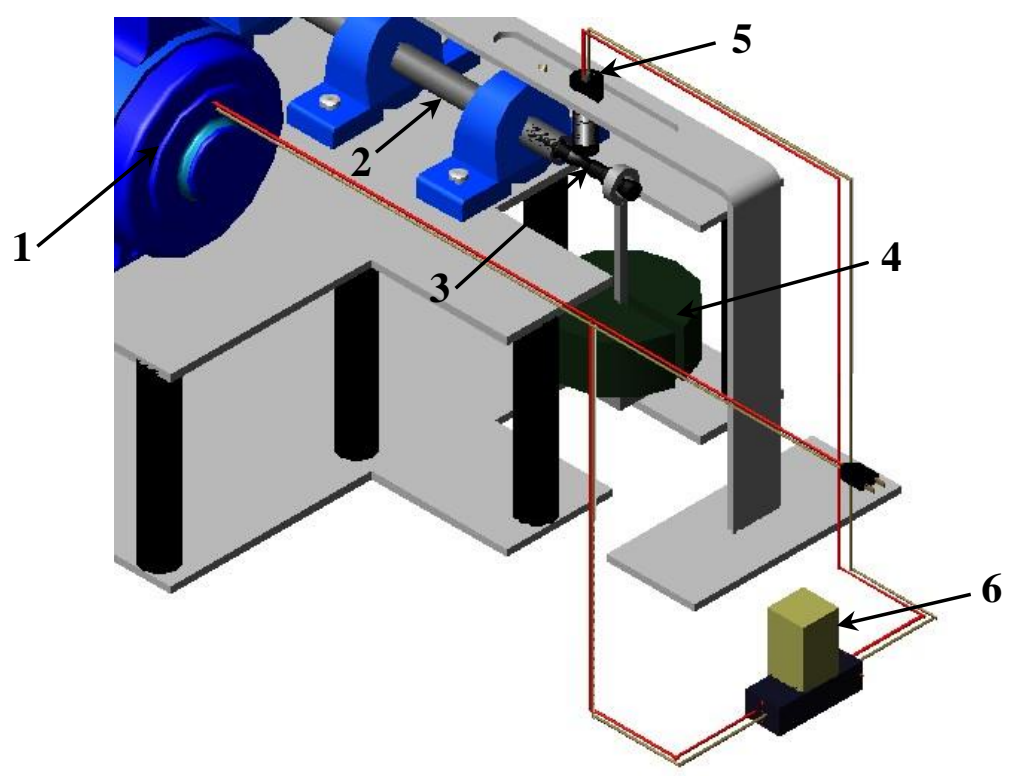

Figure 2: Testing machine. 


\section{Testing conditions and numerical simulations}

Tests were carried out at room temperature $\left(20-24^{\circ} \mathrm{C}\right)$, with a stress ratio of $R=-1$ and environmental humidity comprised between $54-58 \%$. The machining process for all specimens was maintained as constant as possible in order to avoid significant variation in the surface polish; no special control was implemented for this parameter. High temperature is expected at the narrow section when the specimen is tested under loading close to elastic limit. A cooling system with cool air was implemented to maintain the temperature in this zone below $100^{\circ} \mathrm{C}$ in order to restrict the highest testing temperature. Under this condition, it is assumed that there is no variation in the specimen microstructure.

One side of the specimen was fixed and centreed on the rotating axis, the load $P$ was applied on the opposite side in order to obtain the rotating bending fatigue conditions. Numerical simulations were carried out with aid of Visual NASTRAN software (Dominguez Almaraz et al., 2006) to determine the expected load $P$ attaining stresses close the elastic limit of material; Figure 3 presents some results of theses simulations under rotating loading. Using the value $D_{0}=4 \mathrm{~mm}$, simulation results show that an applied load $P=-32.3 \mathrm{~N}$ induces a maximum von Mises stress of about 276 $\mathrm{MPa}$, close to $72 \%$ of the elastic limit for this steel: $386 \mathrm{MPa}$.
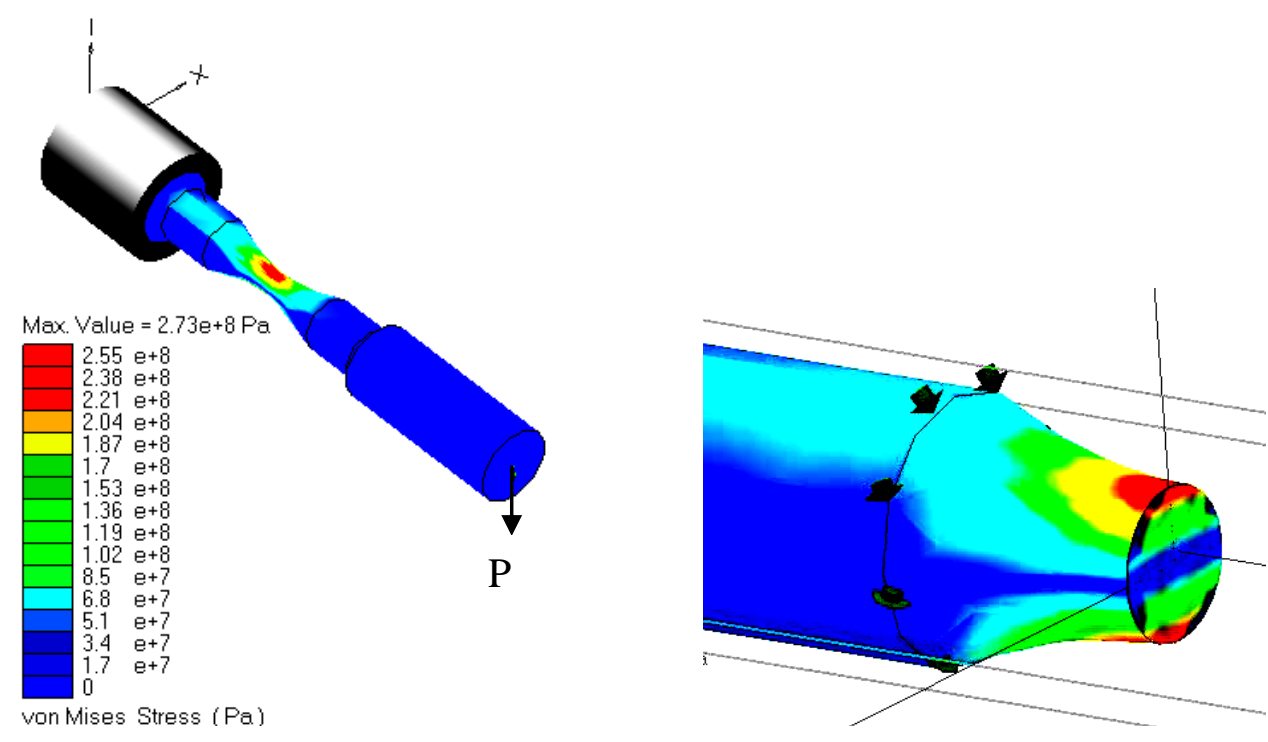

Figure 3: Simulation results on rotating bending fatigue specimen.

\section{RESULTS AND DISCUSSION}

Table 3 presents the results obtained for this low carbon steel using the high speed rotating bending fatigue tests machine. The parameters listed are: narrow section diameter $D_{0}$, applying load $P$, maximum von Mises stress $\sigma_{\max }$, experimental fatigue life $N$, specimen temperature $T_{\max }$ at fracture surface when specimen fails, $S_{D}$ parameter, inclusion factor $I_{F}, \%$ of visual plastic zone $P_{Z}$, and fatigue life $\mathrm{N}_{\mathrm{P}}$ calculated by Eq. 1 .

Crack initiation on AISI-SAE 1018 steel is related to micro-voids coalescence and plastic zones caused by the high stresses close to the elastic limit of the material. Under rotating bending fatigue tests, the high stress zones are located at the fracture 
surface perimeter and decrease to the fracture surface centre: the size of the grooves decreases from the fracture surface perimeter to the centre, as shown in Figure $4 \mathrm{a}$ and $4 \mathrm{~b}$.

These grooves are related to stress concentrations leading to plastic zones and micro-voids coalescence around inclusions, particles or discontinuities (ASM Handbook, 1987). In this work, the micro-plastic zones are defined as progressive plastic deformation observed by the dimples at a scale lower than $30 \mu \mathrm{m}$, Figure 4c. The macro-plastic zones are defined as the observed deformation zones on the fracture surface or the total fracture surface minus the observed granular surface (fast crack growth surface).

Table 3: Experimental parameters and results.

\begin{tabular}{|c|c|c|c|c|c|c|c|c|c|}
\hline Test & $\begin{array}{c}\mathbf{D}_{0} \\
(\mathbf{m m})\end{array}$ & $\begin{array}{c}\mathbf{P} \\
(\mathbf{N})\end{array}$ & $\begin{array}{c}\sigma_{\max } \\
(\mathbf{M P a})\end{array}$ & $\begin{array}{c}\mathrm{N} \\
\text { (cycles) }\end{array}$ & $\begin{array}{l}\mathbf{T}_{\max } \\
\left({ }^{\circ} \mathbf{C}\right)\end{array}$ & $\mathbf{S}_{\mathbf{D}}$ & $\begin{array}{c}\text { Inclusion } \\
\text { factor } \\
\mathbf{I}_{\mathrm{F}}\end{array}$ & $\begin{array}{c}\mathbf{P}_{\mathrm{Z}} \% \\
\text { Plastic } \\
\text { zone }\end{array}$ & $\begin{array}{c}\text { Fatigue } \\
\text { life } \\
\mathbf{N}_{P}\end{array}$ \\
\hline 1 & 4.0 & -32.3 & 276 & 87750 & 70 & 0.51 & 0.08 & 0.43 & 91417 \\
\hline 2 & 4.0 & -32.3 & 276 & 92850 & 68 & 0.61 & 0.10 & 0.51 & 119106 \\
\hline 3 & 4.0 & -32.3 & 276 & 50700 & 60 & 0.36 & 0.02 & 0.34 & 54000 \\
\hline 4 & 4.0 & -32.3 & 276 & 98550 & 70 & 0.57 & 0.08 & 0.49 & 107585 \\
\hline 5 & 4.0 & -32.3 & 276 & 59850 & 70 & 0.40 & 0.10 & 0.30 & 63245 \\
\hline 6 & 4.0 & -32.3 & 276 & 88500 & 75 & 0.49 & 0.04 & 0.45 & 85750 \\
\hline 7 & 4.0 & -32.3 & 276 & 46800 & 70 & 0.35 & 0.00 & 0.35 & 51766 \\
\hline 8 & 4.0 & -32.3 & 276 & 49500 & 75 & 0.38 & 0.08 & 0.30 & 58562 \\
\hline 9 & 4.0 & -32.3 & 276 & 241800 & 97 & 0.90 & 0.10 & 0.80 & 213454 \\
\hline 10 & 4.0 & -32.3 & 276 & 414000 & 80 & - & - & - & - \\
\hline 11 & 4.0 & -32.3 & 276 & 115650 & 60 & 0.66 & 0.08 & 0.58 & 134047 \\
\hline 12 & 4.0 & -32.3 & 276 & 90750 & 80 & 0.54 & 0.06 & 0.48 & 99204 \\
\hline 13 & 4.0 & -32.3 & 276 & 214500 & 90 & 0.84 & 0.05 & 0.79 & 192468 \\
\hline 14 & 4.0 & -32.3 & 276 & 168900 & 82 & 0.74 & 0.06 & 0.68 & 159143 \\
\hline 15 & 4.0 & -32.3 & 276 & 118000 & 74 & 0.66 & 0.08 & 0.58 & 134047 \\
\hline 16 & 4.0 & -32.3 & 276 & 94500 & 71 & 0.56 & 0.06 & 0.50 & 104766 \\
\hline 17 & 4.0 & -32.3 & 276 & 75400 & 78 & 0.46 & 0.04 & 0.42 & 77996 \\
\hline 18 & 4.0 & -32.3 & 276 & 88000 & 68 & 0.49 & 0.07 & 0.42 & 85750 \\
\hline 19 & 4.0 & -32.3 & 276 & 135000 & 81 & 0.64 & 0.07 & 0.57 & 128000 \\
\hline 20 & 4.0 & -32.3 & 276 & 64700 & 73 & 0.42 & 0.09 & 0.34 & 68048 \\
\hline
\end{tabular}




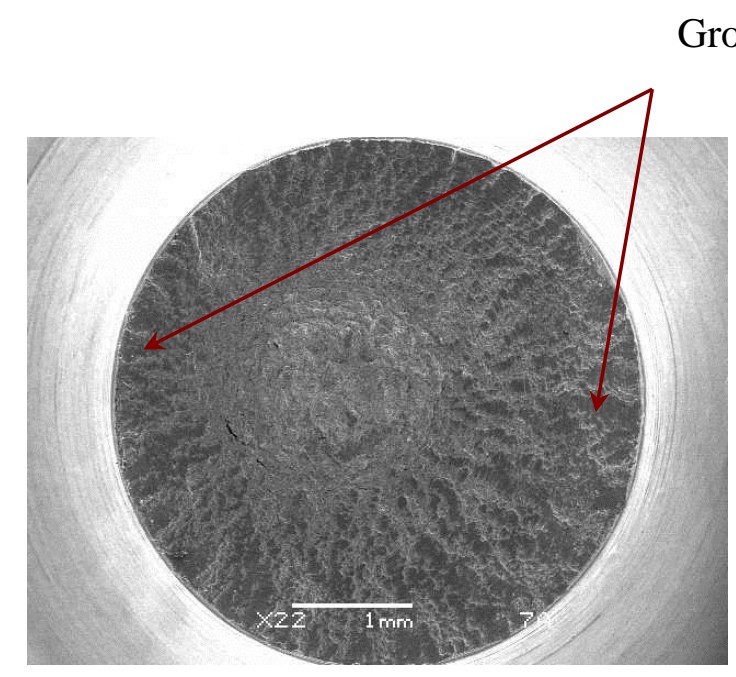

(a)

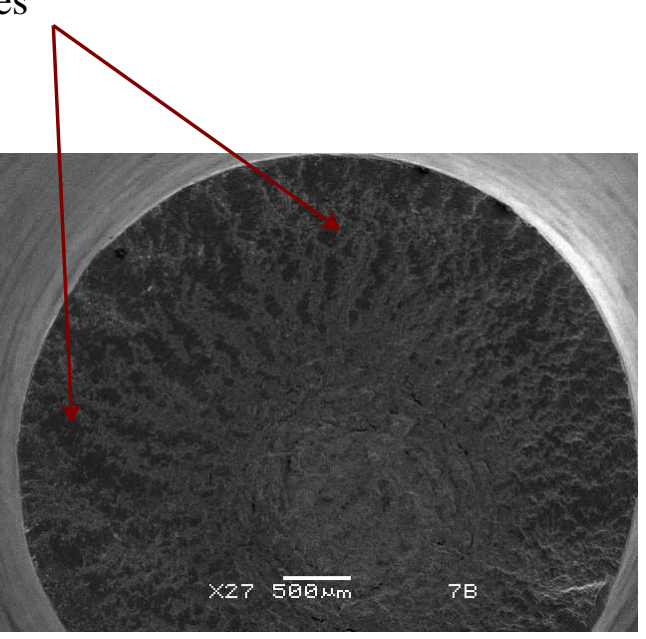

(b)

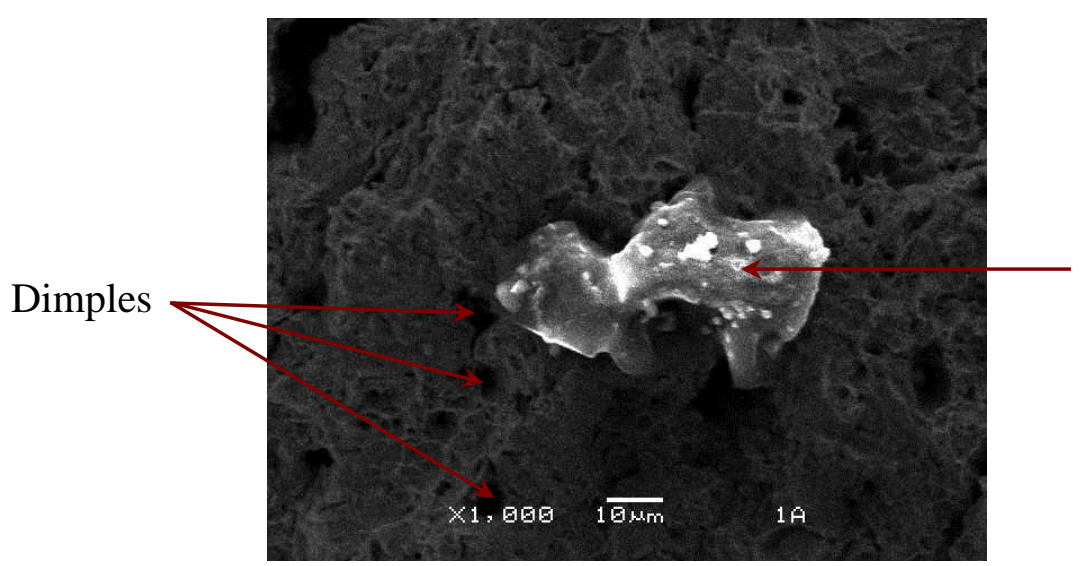

Non metallic inclusion

Figure 4: Fracture surface for specimen No. 7 on Table 3: a) right side, b) left side, c) micro-plastic deformation and inclusion on fracture surface

Rotating bending fatigue tests carried out under loading conditions close to the elastic limit of this steel present a typical fracture surface showing zones of macroplastic deformation and non metallic inclusions. The fracture surface parameters observed for this steel, inclusions and macro-plastic zones, should be related to the fatigue life under rotating bending fatigue tests (Itoga et al., 2004; Mura, 1987; Krausz et al., 1990). An attempt to correlate the fracture surface parameters and fatigue life is as follows: an empirical parameter named 'macro-plastic deformation rate on fracture surface' is proposed to formulate a fatigue life prediction equation for this steel undergoing rotating bending fatigue tests close to the elastic limit:

$$
N_{P}=2.5 \times 10^{5}\left(S_{D}\right)^{1.5}
$$

where $N_{P}$ is the calculated number of cycles to failure and $S_{D}$ is a parameter taking into account the rate of macro-plastic deformation on the total fracture surface and the presence of non metallic inclusions in the macro plastic deformation zone. For the fracture surface of specimen No. 6 on Table $3, S_{D}=0.49$, that is: $N_{P} \approx 85700$ cycles, 
whereas for specimen No. $13, S_{D}=0.84$, then $N_{P} \approx 192400$ cycles. Table 3 shows the calculated values $S_{D}$ for all tested specimens. These values are obtained taking into account the estimated macro-plastic deformation ratio $P_{Z}$ and the presence of crack initiation inclusion (or inclusions) in this zone denoted 'inclusion factor $I_{F}$ ', by Eq. 2:

$$
S_{D}=P_{Z}+I_{F}
$$

Taking specimen 1 on Table 3, Figure 5 shows how the parameters $P_{Z}$ and $I_{F}$ were estimated. Exterior area is related to macro-plastic deformation zone; thus, $P_{Z}$ is the ratio between this area and the total area on fracture surface. Concerning parameter $I_{F}$, it is estimated by the ratio between the "inclusion associated area" and the macro-plastic deformation area. The values for experimental fatigue life $N$ and fatigue life calculated by Eq. $1 N_{P}$, are listed on Table 3 .

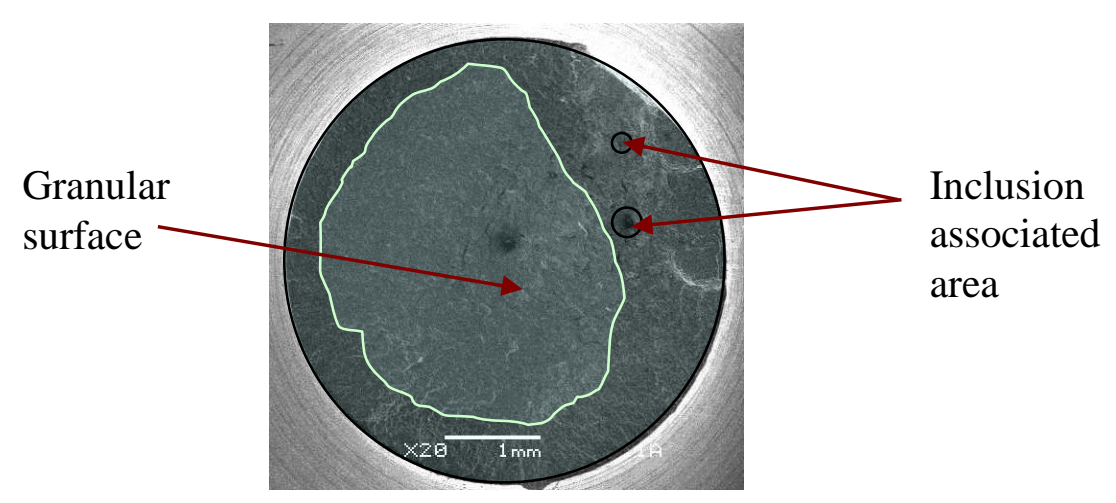

Figure 5: Evaluation of $P_{Z}$ and $I_{F}$ parameters of specimen No 1, Table 3.

Figure 6 presents the $S$ - $N$ curve on experimental results according to Table 3 . The large scattering of results (from $5 \times 10^{4}$ to $2.4 \times 10^{5}$ cycles) should be due to testing a non homogenous material containing non metallic inclusions and presenting different mechanisms of crack initiation: micro-voids coalescence close to inclusions, crystallographic weak localizations, and plastic zones developed on the fracture surface. Nevertheless, the short fatigue lives of tested specimens seem to be associated with the small visual macro-plastic zones on the corresponding fracture surfaces, as is observed in Table 3. This relationship should be explained as follows: a short fatigue life for these specimens is associated with a decrease of the macro-plastic deformation zone at the fracture surface and this implies a capacity reduction for accumulating plastic deformation energy. 


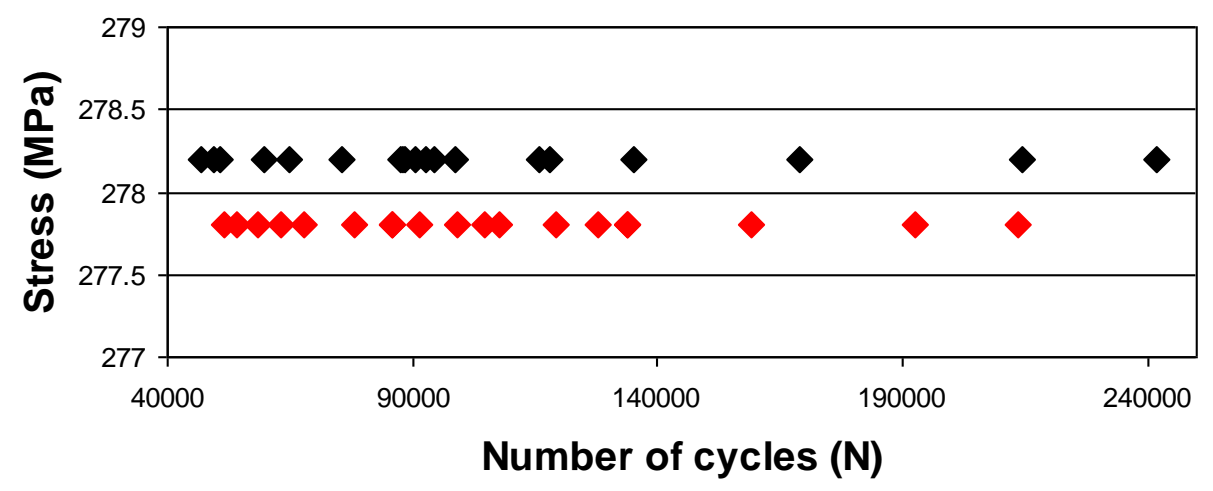

Figure 6: Experimental results in black (plotted at 278.2 MPa), and results obtained by the predicted model, Eq. 1, in red (plotted at $277.8 \mathrm{MPa}$ ).

\section{CONCLUSION}

The fatigue life for AISI-SAE 1018 steel loading close to its elastic limit (72\%), under rotating bending fatigue tests is comprised between $4.7 \times 10^{4}$ and $2.5 \times 10^{5}$ cycles. A model is proposed to predict the fatigue life of this steel under rotating bending fatigue tests at high loading based on the ratio between the macro-plastic deformation zone and the total fracture surface with the presence of crack initiation inclusion or inclusions. Only one value of high stress was studied in this work: $276 \mathrm{MPa}$ or $72 \%$ of the elastic limit; others values for high stress should be tested in order to validate the model. The experimental results for fatigue life agreed with the empirical formulation under the described loading conditions. Nevertheless, further investigations are required for the understanding of micro and macro plastic zones associated with crack initiation and propagation, the role of fatigue dimples and grooves, the presence of discontinuities, or hydrogen, and the different factors leading to stress concentration at different scales: crystallographic, granular and macroscopic.

\section{ACKNOWLEDGEMENTS}

The authors would like to express their gratitude to the University of Michoacan (UMSNH), and the Technological University of Morelia (UTM), Mexico, for the facilities to carry out this work. A special mention of gratitude to the National Council for Science and Technology (CONACYT), in Mexico for the financial support of this project.

\section{REFERENCES}

ASM Handbook (1987) Metals Handbook, Vol. 12, Fractography, ASM International, The Metals Information Society.

Dominguez Almaraz, G.M. (2008) Prediction of very high cycle fatigue failure for high strength steels, based on the inclusion geometrical properties. Mechanics of Materials, 40, 636-640.

Domínguez Almaraz, G.M., Soriano Peña, J.F. and Gutiérrez Sánchez, H. (2006) Rotating bending fatigue simulation of hourglass shape specimen of AISI-SAE C1020 steel. Proc. $9^{\text {th }}$ International Fatigue Congress, Atlanta, GA, USA. 
Itoga, H., Ko, H.-N., Tokaji, K. and Nakajima, M. (2004) Effect of inclusion size on step-wise S-N characteristics in high strength steels. Proc. $3^{\text {rd }}$ VHCF Int. Conf. Eds., Tokyo, Japan, pp. 633-640.

Jung, A. and Schnell, A. (2008) Crack growth in a coated gas turbine superalloy under thermo-mechanical fatigue. International Journal of Fatigue, 30 (2), 286-291.

Krausz, A.S., Dickson, J.I., Immarigeon, J.P.A. and Wallace, W. (1990) Constitutive laws of plastic deformation and fracture. Springer,.

Mura, T. 1987. Micromechanics of Defects in Solids 2 ed. New York, Springer.

Nakajima, M., Tokaji, K., Itoga, H. and Shimizu, T. (2010) Effect of loading conditions on very high cycle fatigue behavior in a high strength steel. International Journal of Fatigue, 32, 475-480.

Nový, F., Činčala, M., Kopas, P. and Bokůvka, O. (2007) Mechanisms of high-strength structural materials fatigue failure in ultra-wide life region. Material Science and Engineering-A, 462, 189-192.

Sakai, T., Lian, B., Takeda, M., Shiozawa, K., Oguma, N., Ochi, Y., Nakajima, M. and Nakamura, T. (2010) Statistical duplex S-N characteristics of high carbon chromium bearing steel in rotating bending in very high cycle regime. International Journal of Fatigue, 32, 497-504.

Sohar, C.R., Betzwar-Kotas, A., Gierl, C., Weiss, B. and Danninger, G.H. (2008) Fatigue behavior of a high chromium alloyed cold work tool steel. International Journal of Fatigue, 30, 1137-1149. 